\title{
The impact of a psychiatry clinical rotation on the attitude of Nigerian medical students to psychiatry
}

\author{
TO Adebowale, AO Adelufosi, A Ogunwale, O Abayomi, TM Ojo
}

Neuropsychiatric Hospital, Aro, Abeokuta, Nigeria

\begin{abstract}
Objective: Undergraduate medical students have ingrained and often negative attitudes towards psychiatry as a field and as a career. This in turn has affected recruitment of graduate medical students into the specialty. Little is known about the impact of psychiatry rotations during undergraduate medical training on students' attitudes about psychiatry and eventual specialty choice in developing countries. This study examined the impact of a psychiatry clinical rotation on medical students' attitudes to psychiatry and possible career choice. Method: Eighty-one and one hundred and six fifth year medical students completed the ATP-30, socio-demographic and career choice questionnaires at the beginning and the end of a four week clinical rotation respectively. Results: The overall attitude of the students to psychiatry was favourable at the beginning of the rotation with significant improvement following the rotation ( $p=0.003$ ). Significant improvement in attitude was observed among female and younger students. Students who indicated preference for specialties other than psychiatry showed a greater improvement in their attitude to psychiatry following the rotation $(p=0.011)$. The rotation however did not enhance students' preference for psychiatry as a future career. Conclusion: The four-week clinical rotation in psychiatry resulted in increased mean attitudinal score, but not in enhanced preference for psychiatry as a career.
\end{abstract}

Keywords: Psychiatry; Attitude; Medical students; Nigeria

Received: $28-04-2011$

Accepted: 28-06-201 1

doi: http://dx.doi.org/10.4314/ajpsy.v15i3.24

\section{Introduction}

Medical students have misperceptions about psychiatry, even before they begin medical school. ${ }^{1}$ This may reflect the 'negative image which psychiatry has among the general populace or it may be due to the impact of 'bad mouthing' by other specialists. ${ }^{2}$ It is against this complex backdrop that recruitment of medical graduates into psychiatry takes place.

Factors such as personality, previous experience with a person with mental illness, medical school experiences, including influence of faculty members have been found to affect the attitude of medical students towards psychiatry. ${ }^{3-5}$ The potential impact of psychiatry clerkships during undergraduate medical training on student attitudes and career choice has been extensively studied, mostly at academic institutions in developed countries. Available studies in Africa have assessed only the general attitude of medical students to psychiatry. 6,7 However, there is a dearth of studies about the impact of psychiatric clinical rotations on the attitude of medical students to psychiatry.

As in many medical schools around the world, the medical curriculum in most Nigerian Universities provide for a rotation in psychiatry though the duration varies. Understanding the potential impact of psychiatry clinical rotations on medical students' attitude to psychiatry and choice as a career may help to enhance recruitment into the specialty.

This study aimed to examine the impact of a 4-week clinical rotation at a Neuropsychiatric hospital in Nigeria on the attitude of medical students to psychiatry and the choice of psychiatry as a career.

\section{Method}

Setting and study population

The study was conducted at the Neuropsychiatric Hospital, Aro, Abeokuta, Nigeria. The hospital is a foremost treatment facility in Nigeria providing specialized mental health care in general adult, child and adolescent, old age and forensic 
psychiatry as well as drug abuse treatment and rehabilitation

Participants were fifth year medical students of the Olabisi Onabanjo University, Ogun state, Nigeria. Fifth year medical students in Nigeria are in the 2nd year of clinical clerkship having spent two year in basic sciences and two years in clinical specialties

The students had a six-week rotation in psychiatry comprising two weeks of didactic lectures followed by the 4week clinical rotation at the Neuropsychiatric Hospital, Aro, Ogun state, which consisted of intensive clinical exposure in addition to classroom lectures and seminars.

\section{Instruments}

The authors designed a brief demographic and career interest questionnaire which was used in obtaining data such as age, gender, marital status, religion and preferred specialty choice following graduation.

Participants also completed the Attitude to Psychiatry questionnaire (ATP-30). The ATP-30 questionnaire is a 30-item scale developed by Burra et $\mathrm{al}^{8}$ which examines the attitude of medical students to psychiatry as a career, psychiatric illness, psychiatrists, psychiatric treatment as well as psychiatric institutions and teaching, on a 5-point Likert scale (e.g. 1 = Strongly agree, 5 = Strongly disagree). Sample questionnaire items include; 'Psychiatrists talk a lot but do very little' (Item 2) and 'I would like to be a psychiatrist' (Item 4). Students' response to the 4th item was also used as a rough indicator of interest in taking up psychiatry as a career. ATP-30 generates a total score between 30 and 150 with a higher score indicating a positive attitude towards psychiatry. The scale has been shown to have good psychometric properties among medical students. ${ }^{8}$ Scores above ninety are indicative of a favorable attitude, scores below 90 signify an unfavourable attitude while a score of 90 indicates a neutral attitude.

\section{Ethical Considerations}

Ethical approval for the study was obtained from the Ethics and Research committee of the Neuropsychiatric hospital, Aro. The nature of the study was explained to the students with assurance that their participation in the study would in no way affect their academic evaluation at the end of the rotation, and anonymity was preserved in the completion of the questionnaires.

\section{Procedure}

One hundred and twenty one students were enrolled in the rotation between January and March 2009. Eighty one (81) and one hundred and six (106) consenting students completed the survey questionnaires at the beginning and at the end of the rotation respectively. The pre- and post-rotation samples were treated independently i.e. not as paired data since paired data would have required some form of identification thereby disallowing anonymity. In addition, this method provided room for the inclusion of all completed questionnaires at both periods. Thus, it helped to remove the problem of attrition, which is a common concern in longitudinal studies of this kind.

A Chi-Square test was used to examine associations between categorical variables while independent sample ttest was utilized for continuous variables. All statistical analyses were completed using SPSS version 15.

\section{Results}

Of the 121 students, 81 and 106 students completed the questionnaires before and after the rotation, giving response rates of $66.9 \%$ and $88 \%$ respectively.

The mean ( \pm s.d) age of the respondents before and after the rotation was $26( \pm 3.14)$ and $26( \pm 2.65)$ years respectively. Their median age was 25years, and this was used to divide the respondents into two age groups (less than or equal to $25 y r s$ and greater than 25yrs). A median split was not favored in the analysis because it would have led to some decrease in sample size with attendant loss in statistical power.There were no significant differences in the age $\left(\chi^{2}=0.06, p=0.972\right)$ and gender $\left(\chi^{2}=0.01, p=0.936\right)$ distributions between the preand post-rotation groups. Socio-demographic and career characteristics are shown in Table I.

\section{Attitude towards Psychiatry}

As shown in Table I, the mean ATP score was 107.96 in the pre-rotation sample and 113.25 in the post-rotation sample, which was significantly higher $(t=3.041, p=0.003)$.

About $22 \%$ of the students expressed definite interest in taking up a career in psychiatry before the rotation and $22.6 \%$ at the end of the rotation $\left(\chi^{2}=2.988, p=0.224\right)$.

\section{Students' characteristics and attitude to Psychiatry}

There was no significant difference between the pre- and post- rotation mean ATP scores for males $(t=1.679, \mathrm{p}=$ 0.096). Although female students had a significantly higher difference in their mean ATP score at the end of the rotation ( $t$ $=-2.657, \mathrm{p}=0.009)$, there was no corresponding change in their intention to become psychiatrists $\left(\chi^{2}=1.965, \mathrm{p}=0.374\right)$.

Younger medical students (i.e. less than or equal to 25years) had significantly higher mean scores in their attitude to psychiatry post-rotation ( $\mathrm{t}=2.440, \mathrm{p}=0.017)$. This did not however enhance their intention to be psychiatrists $\left(\chi^{2}=2.804\right.$, $\mathrm{p}=0.246)$

Students who reported having a preferred area of specialization other than psychiatry at the beginning of the rotation had significantly higher mean scores post-rotation (t $=2.608, p=0.01 \mathrm{l}$ ) while those who were undecided about their career choice or who already chose psychiatry as their preferred area of specialization did not demonstrate such attitudinal change.

\section{Discussion}

This survey is one of the most recent Nigerian studies to evaluate the impact of a clinical rotation in psychiatry on the attitude of medical students to psychiatry. The samples were treated independently to achieve anonymity and thus prevent response bias, as the students may perceive their responses as part of the rotation evaluation. Agreeably, this is a weaker design than a paired design with limitations to inferences from the changes observed.

The medical students in this study generally had an overall favourable attitude towards psychiatry at the beginning of the rotation. This could be attributable to the administration of the ATP-30 Questionnaire after two weeks of classroom lectures in psychiatry prior to commencement of the rotation. In addition, introduction to behavioural sciences at the Olabisi Onabanjo University starts in the fourth year of training and this could partly account for the finding. 


\begin{tabular}{|c|c|c|c|c|c|c|c|c|c|}
\hline VARIABLE & \multicolumn{3}{|c|}{$\operatorname{PRE}(n=81)$} & \multicolumn{3}{|c|}{$\operatorname{POST}(n=106)$} & t & $\chi^{2}$ & $p$ \\
\hline $\begin{array}{l}\text { Age }^{*} \\
\text { Median Age } \\
\leq 25 \text { years } \\
>25 y e a r s\end{array}$ & \multicolumn{2}{|c|}{$\begin{array}{l}25 y e a r s \\
35(43.2) \\
32(39.5)\end{array}$} & & \multicolumn{2}{|c|}{$\begin{array}{l}\text { 25years } \\
47(44.3) \\
42(39.6)\end{array}$} & & & 0.060 & 0.972 \\
\hline $\begin{array}{l}\text { Gender* } \\
\text { Female } \\
\text { Male }\end{array}$ & \multicolumn{2}{|c|}{$\begin{array}{l}35(43.2) \\
45(55.6)\end{array}$} & & \multicolumn{2}{|c|}{$\begin{array}{l}47(44.3) \\
59(55.7)\end{array}$} & & & 0.010 & 0.936 \\
\hline $\begin{array}{l}\text { Preliminary Specialty Choice } \\
\text { No Specialty } \\
\text { Other Specialties } \\
\text { Psychiatry Specialty }\end{array}$ & \multicolumn{2}{|c|}{$\begin{array}{l}49(60.5) \\
27(33.3) \\
5(6.2)\end{array}$} & & \multicolumn{2}{|c|}{$\begin{array}{l}62(58.5) \\
38(35.8) \\
6(5.7)\end{array}$} & & & 0.140 & 0.935 \\
\hline $\begin{array}{l}\text { MEAN ATP SCORES [mean(s.d)] } \\
\text { All Students } \\
\text { Males } \\
\text { Females } \\
\text { Age } \leq 25 y e a r s \\
\text { Age > 25years } \\
\text { Psychiatry Specialty } \\
\text { Other Specialties } \\
\text { No Specialty }\end{array}$ & \multicolumn{2}{|c|}{$\begin{array}{l}107.96(11.27) \\
106.47(12.27) \\
110.34(9.36) \\
107.17(12.08) \\
108.93(10.52) \\
114.00(5.39) \\
107.63(9.72) \\
107.53(12.40)\end{array}$} & & \multicolumn{2}{|c|}{\begin{tabular}{|l|}
$113.25(12.14)$ \\
$110.53(12.18)$ \\
$116.66(11.32)$ \\
$113.79(12.19)$ \\
$112.81(12.19)$ \\
$119.17(13.67)$ \\
$114.92(11.98)$ \\
$111.65(11.98)$
\end{tabular}} & & $\begin{array}{l}3.041 \\
1.679 \\
2.686 \\
2.440 \\
1.705 \\
0.790 \\
2.608 \\
1.769\end{array}$ & & $\begin{array}{l}0.003 \\
0.096 \\
0.009 \\
0.017 \\
0.091 \\
0.450 \\
0.011 \\
0.080\end{array}$ \\
\hline $\begin{array}{l}\text { PSYCHIATRY AS A CAREER† (\%) } \\
\text { All Students } \\
\text { Males } \\
\text { Females } \\
\text { Age } \leq 25 \text { years } \\
\text { Age }>25 \text { years } \\
\text { Other Specialties } \\
\text { No Specialty }\end{array}$ & $\begin{array}{l}\text { YES } \\
22.2 \\
15.6 \\
26.6 \\
31.4 \\
12.5 \\
7.4 \\
22.4\end{array}$ & $\begin{array}{l}\text { NO } \\
44.4 \\
51.1 \\
37.1 \\
40.0 \\
50.0 \\
77.8 \\
30.6\end{array}$ & $\begin{array}{l}\text { UNDECIDED } \\
33.3 \\
33.3 \\
34.3 \\
28.6 \\
37.5 \\
14.8 \\
46.9\end{array}$ & \begin{tabular}{|l} 
YES \\
22.6 \\
20.3 \\
25.5 \\
23.4 \\
19.0 \\
15.8 \\
19.4
\end{tabular} & $\begin{array}{l}\text { NO } \\
33.0 \\
39.0 \\
25.5 \\
29.8 \\
40.5 \\
57.9 \\
21.0\end{array}$ & $\begin{array}{l}\text { UNDECIDED } \\
44.3 \\
40.7 \\
48.9 \\
46.8 \\
40.5 \\
26.3 \\
59.7\end{array}$ & & $\begin{array}{l}2.988 \\
1.536 \\
1.965 \\
2.804 \\
0.891 \\
2.814 \\
1.957\end{array}$ & $\begin{array}{l}0.224 \\
0.464 \\
0.374 \\
0.246 \\
0.641 \\
0.245 \\
0.376\end{array}$ \\
\hline
\end{tabular}

* totals not equal to $n$ on account of missing data.

† Chi square comparisons for those who chose psychiatry as a preferred specialty pre- and post- rotation was excluded because there were no changes in their proportions.

Female medical students had a more positive attitude to psychiatry at the end of the clinical rotation, a finding similar to that of other authors. ${ }^{9,10}$ This may suggest that female medical students could have greater empathy toward people with emotional problems as noted by Reddy et al. ${ }^{9}$ It is not surprising that despite having a favourable attitude to psychiatry, they were not more interested in becoming psychiatrist, suggesting that variables other than attitude determine specialty choice.

The finding that younger medical students in this study had a significant improvement in their attitude to psychiatry post-rotation is similar to that of Al Ansari \& Alsadadi ${ }^{10}$, showing that early clinical exposure may probably exert some influences on the choice of psychiatry as a career. However, further studies will be required to substantiate this.

In this survey, students who indicated preference for specialties other than psychiatry had a significant change in attitude to psychiatry at the end of the rotation compared with students who indicated no preference for any specialty. Such favourable attitude may improve their skill in early identification and referral of patients with psychological problems. It has been suggested that the population of students interested in Internal medicine and Neurology as well as the Humanities could be the source of psychiatric residents. ${ }^{11}$ When efforts are made to make psychiatry appealing during clinical rotations, such students planning to specialize in other fields may eventually consider a career in psychiatry.

Despite the positive impact of the clinical rotation on the attitude of females, younger students and those who had a preferred choice of specialty other than psychiatry, this did not translate into their intention to specialize in psychiatry. It is possible that a complex interplay of factors affect the attitude of medical students to psychiatry and especially factors predating their clinical psychiatric exposure may determine the students' choice of a career in psychiatry. Further investigations into these factors are necessary.

This study was limited by its inability to show which aspects of the clinical rotation influenced the attitude of the students. The experience of direct involvement in patient care, seeing patients who responded well to treatment and 
receiving encouragements from consultants, among others are known to influence the attitude of students to psychiatry during clinical rotations. ${ }^{12}$ In addition, assessing the students immediately after the rotation may not reflect enduring attitudes as a positive change in attitude may be transient. ${ }^{13}$ Furthermore, although it may be argued that the conduct of the survey on two different occasions served the purpose of the students acting as their own internal controls, the 2 week lecture series received prior to the initial survey could have introduced some bias, as it was not possible to control for its effects on the attitude of the students to psychiatry at the beginning of the clinical rotation. Studies evaluating students' attitude to psychiatry before any form of knowledge exposure (academic or clinical) would be able to address this likely bias.

The lower completion rate for the pre-rotation survey could have introduced some bias in terms of inadvertent selection of students with less negative attitude towards psychiatry at the pre-rotation survey and thus, a greater potential for perceiving an improvement in attitude which may not be wholly attributable to the rotation. While the use of a single item (question 4) to ascertain intent to specialize in psychiatry might have the benefit of convenience, its validity may not be substantiated by this study.

The findings of this study substantially support the current practice of a psychiatry clinical rotation as a veritable tool for engendering proper orientation to psychiatry during medical training at academic institutions in Nigeria. In addition, early exposure to a clinical rotation in psychiatry during medical training, when many students are still young, may improve their attitude to psychiatry and stimulate their career intentions in the profession. Such early clinical exposure may help in dispelling misconceptions which young medical students have about psychiatry before such erroneous beliefs are consolidated. Future studies on the impact of a psychiatry clinical rotation in developing countries should focus on examining specific factors or experiences during clinical rotations that influence medical students' attitudes to psychiatry as a field and as a career.

\section{Conclusion}

It is not that our findings are similar to results obtained elsewhere concerning the positive impact of a psychiatric rotation on the attitude of females, younger students and students who had a preferred choice of specialty other than psychiatry. The four-week clinical rotation in psychiatry resulted in increased mean attitudinal score, but not in enhanced preference for psychiatry as a career. The findings of this study provide a contribution to the body of knowledge on the impact of a psychiatric clinical rotation on the attitude of medical students to psychiatry.

\section{References}

1. Feifel D, Moutier CY, Swerdlow NR. Attitudes toward psychiatry as a prospective career among students entering medical school.

American Journal of Psychiatry 1999; 156:1397-1402.

2. Hunt DD, Scott C, Zhong S, Goldstein E. Frequency and effects of negative comments ('badmouthing) on medical students' career choices. Academic Medicine 1996; 71, 665-669.

3. Walton HJ. Personality correlates of a career interest in psychiatry. British Journal of Psychiatry 1969; 115: 211-215.

4. Zimny GH, Sata LS. Influence of factors before and during medical school on choice of psychiatry as a specialty. American Journal of Psychiatry 1986; 143:77-80.

5. Eagle PF, Marcos MD. Factors in medical students' choice of psychiatry. American Journal of Psychiatry 1980; 137:423-7.

6. Ndetei DM, Khasakhala L, Ongecha-Owuor F, Kuria M., Mutiso V, Judy Syanda BA, et al. Attitudes toward psychiatry: A survey of medical students at the University of Nairobi, Kenya. Academic Psychiatry 2008; 32:154-159

7. Laugharne R, Appiah-Poku J, Laugharne MA, Shankar R. Attitudes toward psychiatry among final-year medical students in Kumasi, Ghana. Academic Psychiatry 2009; 33:71-75.

8. Burra P, Kalin R, Leichner P, Waldron JJ, Handforth JR, Jarrett FJ, et al. The ATP 30 - a scale for measuring medical students' attitudes to Psychiatry. Medical Education 1982; 16:31-38.

9. Reddy JP, Tan SMK, Azmi MT, Shaharom MH, Rosdinom R, Maniam T, et al. The effect of a clinical posting in psychiatry on the attitudes of medical students towards psychiatry and mental illness in a

Malaysian medical school. Annals of Academic Medicine Singapore 2005; 34: 505-510.

10. Al-Ansari A, Alsadadi A. Attitude of Arabian Gulf University medical students towards psychiatry. Educational Health 2002; 15:180-188.

11. Abramowitz MZ, Bentov-Gofrit D. The attitudes of Israeli medical students toward residency in psychiatry. Academic Psychiatry 2005; 29:92-95.

12. McParland M, NobleL M, Livingston G, McManus C. The effect of a psychiatric attachment on students' attitudes to and intention to pursue psychiatry as a career. Medical Education 2003;37:447-454.

13. Sivakumar K, Wilkinson G, Toonc B, Grecr S. Attitudes to psychiatry in doctors at the end of their first post-graduate year: two-year follow-up of a cohort of medical students. Psychological Medicine 1986; 16:357-60

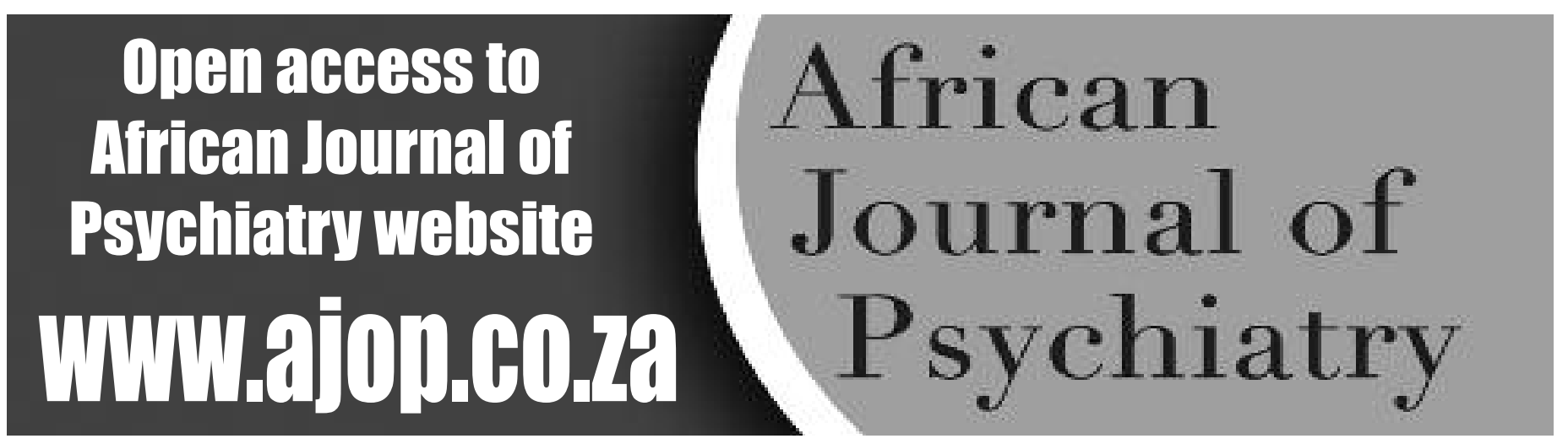

